\title{
Green Chemistry: A New Trend in the Chemical Synthesis to Prevent Our Earth
}

\author{
Shailee Tiwari* and Aakansha Brahmpurkar \\ Department of Pharmaceutical Chemistry, Durgamata Institution of Pharmacy, \\ Parbhani, MS, India \\ *Corresponding Author: Shailee Tiwari, Department of Pharmaceutical Chemistry, \\ Durgamata Institution of Pharmacy, Parbhani, MS, India.
}

Received: March 18, 2021

Published: May 11, 2021

(C) All rights are reserved by Shailee Tiwari and Aakansha Brahmpurkar.

\begin{abstract}
Organic chemistry has played a vital role in the development of diverse molecules which are used in medicines, agrochemicals and polymers. These molecules are synthesized in industries who adopt a process of synthesis which is cost effective; no attention is paid towards release of harmful chemicals. But since last decades special emphasis has been made towards green synthesis which circumvents the above problem. It emphasis on the different tolls of green chemistry like phase transfer catalysis, biocatalysts, aqueous phase reactions, organic synthesis in solid state, microwave assisted synthesis, ultrasound assisted synthesis. It also provides a detailed literature review on green synthesis. The different tools of green chemistry used in synthesis of different molecules are discussed in detail.
\end{abstract}

Keywords: Green Chemistry; Biocatalysts; Phase Transfer Catalysis; Microwave Assisted

\section{Introduction}

\section{History}

P. T. Anastas was the first to use term green chemistry in the year 1991. He used the green chemistry term in a special program launched by the US Environmental Protection Agency (EPA) to implement sustainable development in chemistry and chemical technology by industry, academia and government. European countries have also established some similar awards also.

Within the framework of International Union of Applied and Pure Chemistry, in 1996 the Working Party on Green Chemistry was created. In 1997 the Green Chemistry Institute (GCI) was formed with chapters in 20 countries to facilitate contact between governmental agencies and industrial corporations with universities and research institutes to design and implement new technologies.
In 1997 the first conference highlighting green chemistry was held in Washington. After that many similar scientific conferences were held on a regular basis. In the year 1990s, the first books and journals on the subject of green chemistry were introduced. It included the Journal of Clean Processes and Products (SpringerVerlag) and the Royal Society of Chemistry has also sponsored for Green Chemistry. Some other journals, such as Environmental Science and Technology and the Journal of Chemical Education, have also devoted there some part to green chemistry.

Many different inexpensive measures that can be taken to reduce environmental pollution and exposure to harmful chemicals have been implemented in industrialized societies with good, wellenforced regulations. Small increases in environmental protection now require large investments in money and effort. Is there a better way? Yes why not. The most excellent way is through the practice of green chemistry. 
Green chemistry is defined as "The practice of chemical science and manufacturing in a manner that is safe, sustainable, and nonpolluting and that consumes minimum amounts of materials and energy while gives out little or no waste material". When it was recognized that the chemical reaction production, processing, use, and eventual disposal of chemical products may cause harm when performed incorrectly led to the practice of green chemistry. The main objective of green chemistry and green chemical engineering is to modify or totally redesign chemical products and processes with the objective of minimizing wastes and the use or generation of dangerous materials. Those who follow the 12 principles of green chemistry recognize that they are responsible for any effects on the world that their chemicals or chemical processes may have. Green chemistry increases profits and promoting innovation while protecting human health and the environment. It is also economically regressive and a drag on profits.

Green chemistry is sustainable chemistry. Green chemistry is sustainable in several important respects:

- Economic: At a high level of sophistication green chemistry normally costs less in strictly economic terms in comparison to other conventional synthesis routes. (To say nothing of environmental costs) than chemistry as it is normally practiced.

- Materials: Green chemistry is also sustainable with respect to materials by efficiently using materials, maximum recycling, and minimum use of virgin raw materials.

- Waste: Green chemistry is sustainable with respect to wastes by reducing insofar as possible or even totally eliminating their production.

\section{Green chemistry and synthetic chemistry}

The branch of chemical science involving with the developing means of making novel chemicals and developing improved ways of synthesizing existing chemicals is called as Synthetic chemistry. The involvement of synthetic chemists in the practice of environmental chemistry is a key aspect of green chemistry. The major objective of Synthetic chemists is always been to make new substances and to make them cheaper and better, have come relatively late to the practice of environmental chemistry.

Before environmental, health and safety issues gained their current prominence, the economic aspects of chemical manufacture and distribution were relatively simple and straightforward. The economic factors involved included costs of feedstock, energy requirements, and marketability of product. Now, however, costs must include those arising from regulatory compliance, liability, end-of-pipe waste treatment, and costs of waste disposal. Green chemistry eliminates or greatly reduces the additional costs that are associated with meeting environmental and safety requirements of conventional chemical manufacture, by eliminating or to a large amount reducing the use of toxic or hazardous feedstocks and catalysts and also the generation of dangerous or hazardous intermediates and byproducts.

Some of the challenges for chemists include the discovery and development of new synthetic pathways using alternative feedstocks or more selective chemistry, identifying alternative reaction conditions and solvents for improved selectivity and energy minimization and designing less toxic and inherently safer chemicals. In process of chemical synthesis, the ideal will be a combination of a number of health environmental, and safety, and economic targets figure 1.

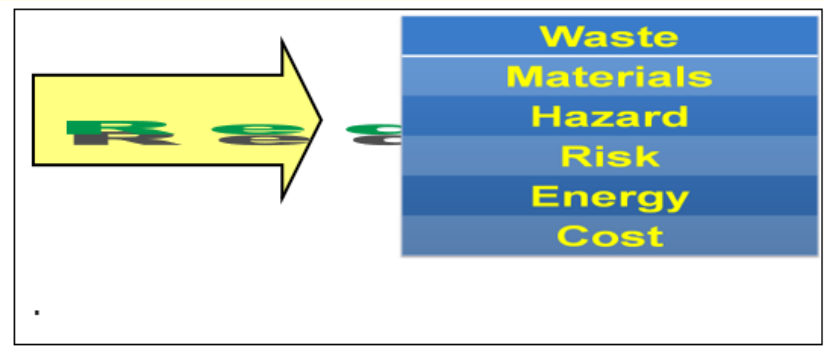

Figure 1: The ideal synthesis.

\section{The 12 principles of green chemistry}

Green chemistry is commonly presented as a set of twelve principles proposed by Anastas and Warner [1]. The principles comprise instructions for professional chemists to implement new chemical compounds, new syntheses and new technological processes. The first principle describes the basic idea of green chemistry is protecting the environment from pollution. The remaining principles are focused on such issues as atom economy, toxicity, solvent and other media using consumption of energy, application of raw materials from renewable sources and degradation of 
chemical products to simple, nontoxic substances that are friendly for the environment.

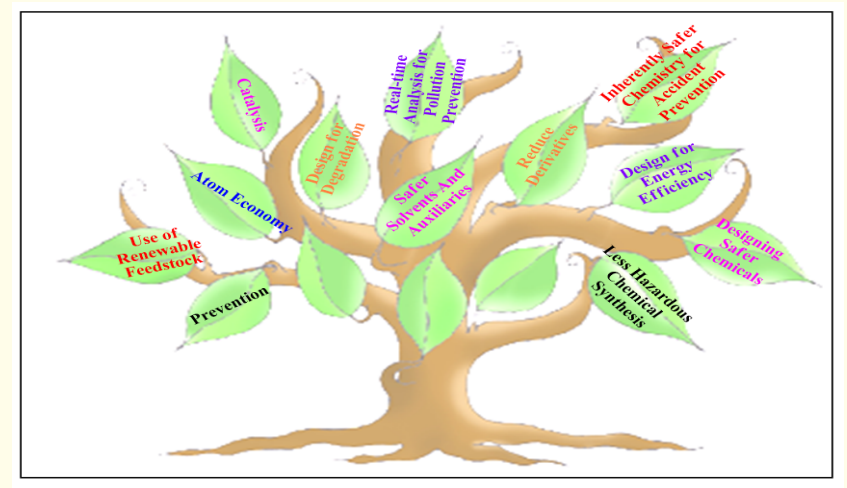

Figure 2: The 12 principles of green chemistry.

The selected examples for implementing the 12 principles in laboratory and industry are presented in table 1.

Tolls of green chemistry: replaced traditional Green catalyst

Catalyst plays a major role in establishing the economic strength of the chemical industry and the clean technology revolution in the industry will provide new opportunities for catalysis and catalytic processes. Following are some different types of catalysts used.

\section{Acid catalysts}

The traditional catalyst hydrogen fluoride, an extremely corrosive, hazardous and toxic chemical used in the production of linear alkylbenzenes, has been successfully replaced by a solid acid catalyst, viz. Flurorided silica-alumina catalyst, it does not require special material of construction, involves minimizing the operating costs and obviates the need for an acid scrubbing system and waste disposal of calcium fluoride [12].

Traditional corrosive monomeric Lewis acids have been replaced with microencapsulated Lewis acids in the reactions like Michael [13], Friedel Crafts [14], Mannich [15], Iminoaldol [16] reactions.

\section{Oxidation catalysts}

A large number of supported reagents have been used in the liquid phase partial oxidation of organic substrates $[17,18]$. There

\begin{tabular}{|c|c|c|}
\hline Sr. no & Principle & Example \\
\hline & Prevention & $\begin{array}{l}\text { Use of solvent less sample } \\
\text { preparation technique [2]. }\end{array}$ \\
\hline & Atom Economy & $\begin{array}{c}\text { Hydrogenation of carboxylic } \\
\text { acid to aldehyde using solid } \\
\text { catalyst }\end{array}$ \\
\hline & $\begin{array}{l}\text { Less Hazardous } \\
\text { Chemical } \\
\text { Syntheses }\end{array}$ & $\begin{array}{l}\text { Adipic acid synthesis by oxida- } \\
\text { tion of cyclohexene by using } \\
\text { hydrogen peroxide [3]. }\end{array}$ \\
\hline & $\begin{array}{l}\text { Designing Safer } \\
\text { Chemicals }\end{array}$ & $\begin{array}{l}\text { New, less Hazardous pesticide } \\
\text { (eg. Spinosad) [4]. }\end{array}$ \\
\hline & $\begin{array}{l}\text { Safer solvents and } \\
\text { auxiliaries }\end{array}$ & $\begin{array}{l}\text { Supercritical fluid extraction, } \\
\text { synthesis in ionic liquid [5]. }\end{array}$ \\
\hline & $\begin{array}{l}\text { Design for energy } \\
\text { efficiency }\end{array}$ & $\begin{array}{c}\text { Polyolefens polymers } \\
\text { alternative to PWC (polymeriza- } \\
\text { tion may be carried with lower } \\
\text { energy consumption) [6]. }\end{array}$ \\
\hline & $\begin{array}{l}\text { Use of Renewable } \\
\text { Feedstocks }\end{array}$ & Production of surfactants [7]. \\
\hline & $\begin{array}{c}\text { Reduce } \\
\text { Derivatives }\end{array}$ & $\begin{array}{l}\text { On-fiber derivatization vs } \\
\text { derivatization in solution in } \\
\text { sample preparation [8]. }\end{array}$ \\
\hline & Catalysis & $\begin{array}{c}\text { Efficient Au (III) catalyzed } \\
\text { synthesis b-enaminones from } \\
\text { 1,3-dicarbonyl compounds and } \\
\text { amines [9]. }\end{array}$ \\
\hline & $\begin{array}{l}\text { Design for } \\
\text { Degradation }\end{array}$ & $\begin{array}{l}\text { Synthesis of biodegradable } \\
\text { polymers [10]. }\end{array}$ \\
\hline & $\begin{array}{c}\text { Real-time analysis } \\
\text { for Pollution } \\
\text { Prevention }\end{array}$ & $\begin{array}{l}\text { Use of in line analyzers for } \\
\text { water waste monitoring }\end{array}$ \\
\hline & $\begin{array}{l}\text { Inherently Safer } \\
\text { Chemistry for } \\
\text { Accident } \\
\text { Prevention }\end{array}$ & $\begin{array}{c}\text { Di-Me carbonate (DMC) is } \\
\text { an environmentally friendly } \\
\text { substitute for di-Me sulfate Me } \\
\text { halides in methylation reaction } \\
\text { [11]. }\end{array}$ \\
\hline
\end{tabular}

Table 1: Examples of implementation of green chemistry principles into practice.

has been considerable success in the use of molecular sieves in commercial units [19]. The most important application of titanium silicates is the hydroxylation of phenol, which gives mixtures of catechol and hydroquinone. The process is clean, giving excellent conversion to product with very little waste. 


\section{Basic catalysts}

The industrial applications of basic catalysts are in the alkylation of phenol, side chain alkylation and isomerisation reactions $[20,21]$.

\section{Polymer supported catalysts}

The conventional catalyst which is normally used in the homogenous phase is linked to a polymer backbone and in this form to catalyze different reactions. Some of the polymer supported catalysts [22] are Polystyrene-aluminium chloride, Polymeric super acid catalysts, Polystyrene-metalloporphyrins, Polymer Supported Photo sensitizers, Polymer Supported Phase Transfer catalysts.

\section{Phase-transfer catalysis in green synthesis}

Most of the syntheses require a number of steps in which additional reagents, catalysts and solvents are used. In addition to the syntheses of the desired products, some waste material is generated in the process, the disposal of which causes problems and also may led to environmental pollution. In regards to this, attempts have been made to use procedures that minimize these problems. One of the most efficient and general and methodologies that takes care of the above problems is to use a phase transfer catalyst (PTC) [23-25]. These type of catalyst, are soluble in water as well as in the organic solvents.

The PTC reaction, in fact, is a methodology for accelerating the reaction between water insoluble organic compounds and water soluble reactants. The basic function of PTC is to transfer the anion from the aqueous phase to the organic phase. As a typical example, the reaction of 1-chlorooctane with $\mathrm{NaCN}$ in water does not give 1 -cyanooctane even if the reaction mixture is stirred for several days. However, if a small quantity of an appropriate PTC is added the product is formed in about $2 \mathrm{hr}$ giving $95 \%$ yield.

PTC used is the quaternary 'onium' salts, such as ammonium, phosphonium, antimonium and tertiary sulphonium salt. In practice, however, only a limited number of ammonium and phosphonium salts are widely used. Some of the PTCs normally used are [23-25]. Aliquat 336: methyl trioctyl ammonium chloride, $\mathrm{N}^{+} \mathrm{CH}_{3}\left(\mathrm{C}_{8} \mathrm{H}_{17}\right) \mathrm{Cl}^{-}$, Benzyl trimethyl ammonium chloride or bromide, $\mathrm{N}^{+}\left(\mathrm{C}_{2} \mathrm{H}_{5}\right)_{3} \mathrm{CH}_{2} \mathrm{C}_{6} \mathrm{H}_{5} \mathrm{X}^{-}(\mathrm{X}=\mathrm{Cl}$ or $\mathrm{Br})$, Benzyl triethyl ammonium chloride or bromide, $\mathrm{N}^{+}\left(\mathrm{C}_{2} \mathrm{H}_{5}\right)_{3} \mathrm{CH}_{2} \mathrm{C}_{6} \mathrm{H}_{5} \mathrm{X}^{-}(\mathrm{X}=\mathrm{Cl}$ or $\mathrm{Br})$, Tetra-n-butyl ammonium chloride or bromide, chlorate or hydroxide, $\mathrm{N}^{+}(\mathrm{n}-\mathrm{Bu})_{4}$
$\mathrm{X}^{-}(\mathrm{X}=\mathrm{Cl}$ or $\mathrm{Br})$, Cetyltriethyl ammonium chloride or bromide $\mathrm{N}^{+} \mathrm{CH}_{3}$ $\left(\mathrm{CH}_{3}\right)_{3}\left(\mathrm{CH}_{2}\right)_{15} \mathrm{CH}_{3} \mathrm{X}^{-}(\mathrm{X}=\mathrm{Cl}$ or $\mathrm{Br})$, Benzyl tributyl ammonium chloride, $\mathrm{C}_{6} \mathrm{H}_{5} \mathrm{CH}_{2}\left(\mathrm{n}-\mathrm{C}_{4} \mathrm{H}_{9}\right)_{3} \mathrm{~N}^{+} \mathrm{Cl}$, Benzyl triphenylphosphonium iodide, $\mathrm{C}_{6} \mathrm{H}_{5} \mathrm{CH}_{2}\left(\mathrm{C}_{6} \mathrm{H}_{5}\right)_{3} \mathrm{P}^{+} \mathrm{I}^{-}$.Besides the above, another catalyst, crown ether is also widely used as PTC.

It is well known that PTC reactions have considerable advantages over other conventional procedures. PTC reactions:

- Are fast and do not require vigorous conditions.

- Do not require expensive aprotic solvents.

- The reaction usually occurs at low temperatures.

- The reaction is conducted in water and hence do not require anhydrous condition.

- With the help of PTC the anion is made available in the organic solvent and so the nucleophilicity increases.

- Use of strong bases (like alkoxide, sodamide, sodium hydride) in the reaction is avoided. The reaction proceeds even with $\mathrm{OH}^{-}$as it become strong nucleophile in presence of PTC.

- Except the reactions which are sensitive to water, all other reactions can be carried out by PTC.

- The reactions which do not proceed in the normal way can be made to proceed in good yields.

E.g. The PTC technique provides a simple method for conducting Williamsons ether synthesis. Use of excess alcohol or alkyl halide, lower temperature and larger alcohol give higher yield of ethers. Attempts to prepare ethers from alcohols by reacting with dimethlysulphate in aqueous $\mathrm{NaOH}$ or even by the use of alkali metal alkoxide have been unsuccessful. However, use of PTC gives high yield of ethers [26].

\section{Microwave induced green synthesis}

The use of Microwave has led to the substantial savings in time for many syntheses in the laboratory as well as in industry. Microwave induced reaction can be carried out in water or in organic solvents. The organic solvents if used are required in small quantities. The most important feature of Microwaves induced reactions is that these can be carried out in solid state, i.e. without the use of any solvent.

Microwave may be considered as a more efficient source of heating than the conventional steam, since the energy is directly 
imparted to the reaction medium rather than the walls of the reaction vessel. In fact, the rapid heating capability of the Microwave leads to the considerable saving in dissolution or the reaction time. The smaller volume of solvent required contributes to saving of cost and diminishes the waste disposal problem $[27,28]$.

It is possible to carry out a number o Microwave organic synthesis. These syntheses are grouped in the following three categories:

- Microwave-assisted reaction in water.

- Microwave- assisted reaction in organic solvent.

- Microwave solvent free reactions (solid state reactions)

Application of Microwave irradiation in organic reactions had added a new dimension to solid phase synthesis. By the use of this technique, it is now possible to carry out reactions without the use of toxic or other solvents, which is one of the major problems associated with the green synthesis. In these, the reactants are dissolved in a suitable solvent like water, methylene chloride, alcohol etc. And the solution stirred with a suitable adsorbent or solid support like silica gel, phyllosilicate or alumina. After stirring the solvent is removed in vacuo and the dried solid support on which the reactants have been adsorbed are used for carrying out the reaction under microwave irradiation.

E.g. Hydrolysis of benzyl chloride with water in microwave oven gives $97 \%$ yield [29] of benzyl alcohol in $3 \mathrm{~min}$. The usual hydrolysis in normal way takes about $35 \mathrm{~min}$.

\section{Ultrasound assisted green chemistry}

The word Ultrasound has become common knowledge due to the widespread use of Ultrasound scanning equipments in medical applications. Sound waves having frequencies higher than those to which the human ears can respond are known as Ultrasound.

The Ultrasound is generated with the help of an instrument having an Ultrasonic tranducer, a device by which electrical or mechanical energy can be converted into sound energy. The most commonly used are the electromechanical transducers which convert energy into sound.

The term "sonochemistry" is used to describe the effect of Ultrasound waves on chemical reactivity. Ultrasound assisted organic synthesis gives excellent yields compared to other reactions. It can dramatically affect the rates of chemical reactions and is helpful for a large number of organic transformations. In fact, a combination of sonication with other techniques, e.g., phase transfer technique, reactions in aqueous media etc. give best results. Sonication has also been shown to stimulate microbiological reactions.

\section{Biocatalysts in organic synthesis}

The most important conversions in the context of green chemistry are with the help of enzymes. Enzymes are also called as biocatalysts and the transformations are referred to as biocatalytic conversions. It is well known that most of the antibiotics have been prepared using enzymes.

The biocatalytic conversions have many advantages in relevance to green chemistry. Some of these are given below:

- Most of the reactions are carried out in aqueous medium at ambient temperature and pressure.

- The biocatalytic conversions normally involve only one step.

- Protection and deprotection of functional groups is not necessary.

- The reactions are fast reactions.

- The conversions are stereospecific.

One of the most common examples is the biocatalytic conversion of Penicillin into 6- APA by the enzyme 'Penacylase'. The special advantage of the biochemical reactions is that they are chemo selective, regioselective and stereo selective. Also, some of the biochemical conversions are generally not possible by conventional chemical means. A number of diverse reactions are possible by biocatalytic processes, which are catalyzed by enzymes. The major six classes of enzymes and the type of reactions they catalyses are Oxidoreductases, Transferases, Hydrolases, Lyases, Isomerases, Ligases.

\section{Application of enzymes}

- A number of commercial applications of isomerases and lyases are recorded. For example, glycosidases are used in large quantity in conversion of corn starch to glucose [30] and glucose isomerise catalyses the equilibration of fructose and glucose [31].

- Aspartic acid is prepared by addition of ammonia to fumaric acid in a reaction catalyzed by aspartate [32].

- Malic acid is obtained by hydration of fumaric acid by the enzyme fumarase [33]. 
- Enantioselective condensation of HCN with aldehydes is catalyzed by cyanohydrolases from several other sources [34].

- S- adenosylhomocysteine can be synthesized from homocysteine and adenosine by adenosylhomocysteine hydrolase [35].

- Ester group at Sn-1 and Sn-2 positions of glycerol moiety can be hydrolyzed by phospholipases $A_{1}$ and $A_{2}$ respectively [36].

Aqueous phases reactions

The use of water as a solvent for carrying out organic reactions was non-existent till about the middle of the $20^{\text {th }}$ century. In view of the environmental concerns caused by pollution of organic solvents, chemists all over the world have been trying to carry out organic reactions in aqueous phase. The advantage of using water as a solvent is it cost, safety and simple operation. Water has the highest value for specific heat of all substances. Its unique enthalpic and entropic properties have led the chemists to use it as a solvent in organic reactions.

Under high pressure and temperature, ordinary water behaves very differently [37]. The electrolytic conductance of aqueous solutions increases with increase in pressure. However, for all other solvents the electrical conductivity of solutions decreases with increase in pressure. This unusual behavior of water is due to its peculiar associative properties [38].

\section{Some important application}

- Synthesis of antifungal based on aqueous Diels-Alder reaction [39].

- Intramolecular version Diels-Alder reaction with a dienecarboxlate was used in synthetic study of the antibiotic ilicicolin $\mathrm{H}[40]$.

- Vinyl sulphones can be stereospecifically reduced to the corresponding olefins with sodium dithionite in aqueous medium [41].

- Electrochemical oxidation of primary alcohols to carboxylic acids [42].

- Electrochemical oxidation of secondary alcohols to ketones [43].

- Electrochemical oxidation of vicinal diols to carboxylic acids [44].
Organic synthesis in solid state

The earlier belief that no reaction is possible without the use of a solvent is no more valid. It is now known that many of reactions occur in solid state without the solvent. In fact in a large number of cases, such reactions proceed more efficiently and with more selectivity compared to reactions carried out in solvents. Such reactions are more beneficial than the conventional reactions since they are simple to handle, reduce pollution, and in comparison to other conventional reactions are comparatively cheaper to operate and are especially of significant value in industry. Solvent free organic synthesis and transformations are industrially useful and largely green.

The organic synthesis in solid phase will be presented in two parts:

- Solid phase organic synthesis without using any solvent.

- Solid supported organic synthesis.

Solid phase organic synthesis without using any solvent

In this type of organic synthesis no solvent is used during the reactions. Solid phase bromination is known [45] since 1963 but systemic work was done in 1987. It was found [46] that crystalline cinnamic acid on bromination gives exclusively the erythro isomer, but its chlorination gives the threo and erythro isomers in 88 and $12 \%$ yields, respectively.

\section{Solid supported organic synthesis}

In these reactions, the reactants are stirred in a suitable solvent. The solution is stirred thoroughly with a suitable adsorbent or solid support like silica gel, alumina, phyllosilicate. After stirring, the solvent is removed in vacuo and the dried solid supports on which the reactants have been adsorbed are used for carrying the reaction under microwave irradiation.

\section{Literature review on green chemistry}

PengZhang, Tianbin $\mathrm{Wu}$ [47], has prepared $\mathrm{Ru}-\mathrm{Zn}$ supported on hydroxyapatite as an effective catalyst for partial hydrogenation of benzene. Design and preparation of efficient and greener catalytic systems for partial hydrogenation of benzene to cyclohexene is an interesting topic in green chemistry. In this work, $\mathrm{Ru}$ and $\mathrm{Ru}-\mathrm{Zn}$ catalysts supported on hydroxyapatite (HAP), which is nontoxic and abundant in nature, were prepared via the simple 
ion-exchange method. The catalysts were characterized by powder X-ray diffraction (XRD), transmission electron spectroscopy (TEM), $\mathrm{X}$-ray photoelectron spectroscopy (XPS) and nitrogen adsorptiondesorption methods. The influences of $\mathrm{Ru} / \mathrm{Zn}$ molar ratio, reaction temperature, pressure, reaction time, and amount of modifier $\mathrm{NaOH}$ on the partial hydrogenation of benzene were studied in detail. It was demonstrated that metallic nanoparticles of less than $2 \mathrm{~nm}$ were dispersed uniformly on the surface of the HAP, and the bimetallic $\mathrm{Ru}-\mathrm{Zn} / \mathrm{HAP}$ catalysts showed high activity and selectivity. The yield of cyclohexene could reach $33 \%$ over Ru-Zn/HAP at the optimized conditions, and the catalyst could be reused at least four times without obvious loss of the activity and selectivity refer figure 3 .

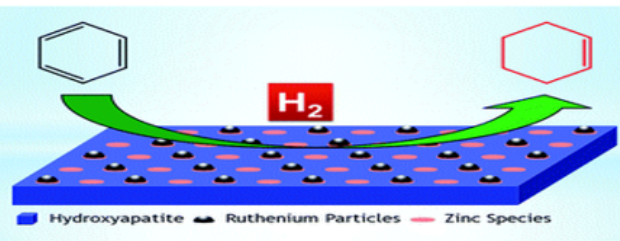

Figure 3: Partial hydrogenation of benzene to cyclohexene supported on hydroxyapatite.

GongzhouChen, Shijian Wu, Hongli Liu [48] has reported that Palladium supported on an acidic metal-organic framework as an efficient catalyst in selective aerobic oxidation of alcohols. The catalyst was shown to be able to efficiently catalyze aerobic oxidation even at ambient temperature using air instead of pure $\mathrm{O}_{2}$. The scheme used is shown in figure 4.

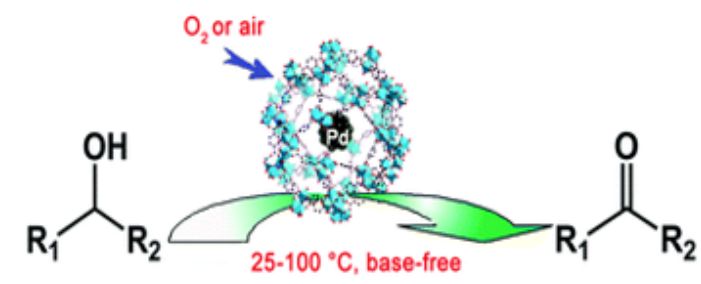

Figure 4: Aerobic oxidation of alcohols in presence of Palladium.
Malik P., D. Chakraborty [49] has reported a green synthesis method for the Transformation of aromatic and aliphatic alcohols in the equivalent carboxylic acids and ketones. Various aromatic, aliphatic and conjugated alcohols were transformed into the corresponding carboxylic acids and ketones in good yields with aq 70\% $t$-BuOOH in the presence of catalytic amounts of bismuth (III) oxide. The scheme used is shown in figure 5.

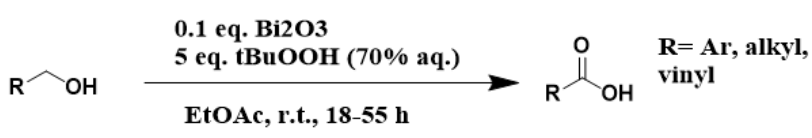

Figure 5: Green synthesis of aliphatic alcohols to carboxylic acids and ketones.

Z. Mao, Y. Jia, W. Li, R. Wang [50] has reported the highly enantioselective Michael addition of malonates to $\alpha, \beta$-unsaturated ketones in water is catalyzed by a primary-secondary diamine catalyst containing a long alkyl chain. This asymmetric Michael addition process allows the conversion of various $\alpha, \beta$-unsaturated ketones.

F. Jahani, B. Zamenian, S. Khaksar, M. Taibakhsh [51] has reported the direct synthesis of $\alpha$-hydroxyphosphonates via reaction of aldehydes and ketones with trimethylphosphite in the presence of catalytic amounts of pyridine 2,6-dicarboxylic acid in water is simple, cost-effective and environmentally benign. The scheme used is shown in figure 6.

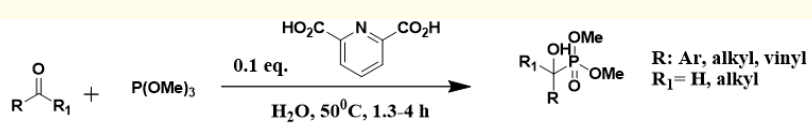

Figure 6: Green synthesis of $\alpha$-hydroxyphosphonates.

P. Nun, J. Martinez, F. Lamaty has reported [52] Borono-Mannich reactions in solvent-free conditions under microwave irradition with short reaction time. Full conversion of the starting materials towards the expected product was achieved, starting from stoichiometric quantities of reactants, avoiding column chromatography. No purification step other than an aqueous washing was required. The scheme used is shown in figure 7. 


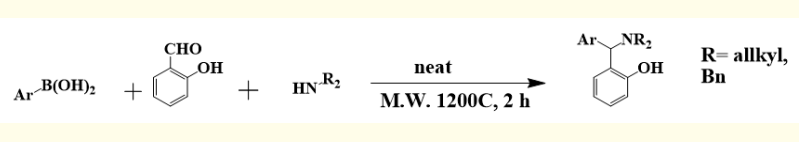

Figure 7: Borono-Mannich reactions in solvent-free conditions.

Anna PratimaNikalje* and DeepikaVyawahare has reported [53] have reported eco friendly synthesis of 2, 4-substituted -2, 3dihydro -1,5-benzothiazepine derivatives as novel anticonvulsant and central nervous system (CNS) depressant agents having lesser side effects, as shown in figure 8.

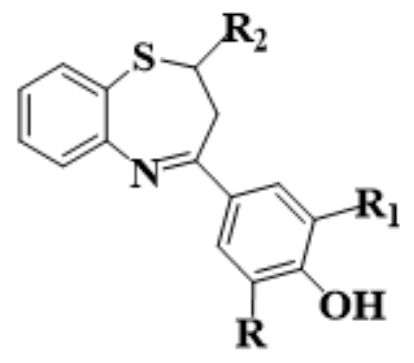

Figure 8: 2, 4-substituted-2,3-dihydro-1,5-benzothiazepines.

YasunariMonguchi, Kei Nozaki, ToshihideMaejima., et al. [54] has reported Huisgen cycloaddition of mono-substituted alkynes to azides in the presence of triethylamine under totally solvent-free conditions to afford the corresponding 1,4-disubstituted 1,2,3-triazoles in excellent yields and in a completely regioselective manner. Furthermore, the Huisgen cycloaddition was found to effectively proceed without addition of triethylamine by the use of $7 \% \mathrm{Pd} /$ CR2 0 as a catalyst. The scheme used is shown in figure 9.

Jean Marcel R. [55] have reported production and upgrading of 5-hydroxymethylfurfural using heterogeneous catalysts and biomass-derived solvents.

Malhotra P, Pattan S, Nikalje APG [56] has synthesized 3, 5diarylsubstituted -2pyrazolines using an efficient, rapid, ecofriendly and cost effective microwave assisted method.

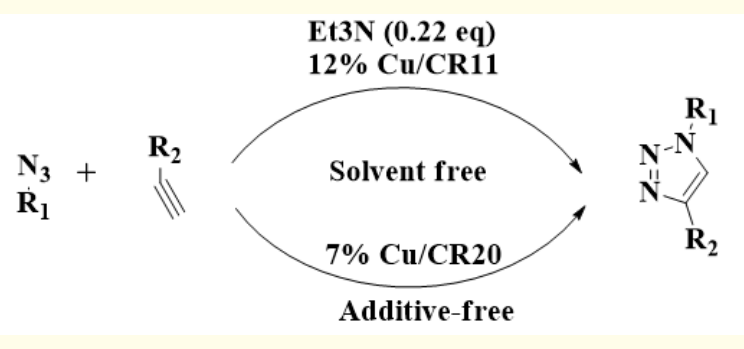

Figure 9: Huisgencycloaddition in solvent free condition.

RocíoGarcía-Álvarez, Pascale Crochet and VictorioCadierno [57] has reported metal-catalyzed synthetic approaches of amides conducted in an environmentally friendly aqueous medium. This can be explained through following figure 10 .

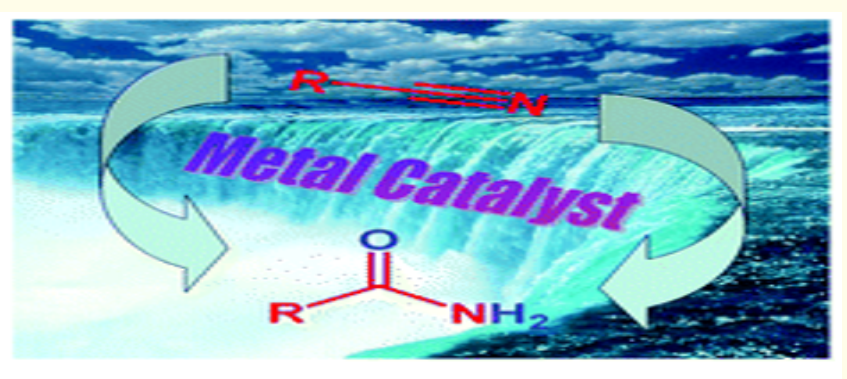

Figure 10: Metal-catalyzed synthetic approaches of amides.

Ada Marinella Truscello, Cristian Gambarotti., et al. [58] has synthesized aryloxypropanediols from glycerol using one pot synthesis method.Catalyst and un-reacted reagent can be recycled used during this process.

Chang cheng Jing, Taoda Shi, Dong Xing, XinGuo and Wenhao Hu [59] has reported a highly efficient three-component reaction of $\alpha$-diazo ester, water and isatin by using $\mathrm{CuSO}_{4}$ as the catalyst. In this reaction, water was used as both a reactant but also the solvent.

Nikalje AG., et al. [60] have synthesized novel 1, 5-benzothiazepines and evaluated for anticonvulsant activity. 1,3-substitutedprop-2-en-1-one were synthesized by microwave -assisted. 
S. Barata-Vallejo, A. Postigo [61] has reported Intermolecular addition of perfluoroalkyl radicals on electron rich alkenes and alkenes with electron withdrawing groups in water, mediated by silyl radicals gives perfluoroalkyl-substituted compounds in good yields.

J.-G. Kim, D. O. Jang [62] has reported a simple, practical, and catalytic method for the $\mathrm{N}$-formylation in the presence of molecular iodine as a catalyst under solvent-free conditions. By using this method $\alpha$-Amino acid esters can be converted without epimerization. The scheme used is shown in figure 11.

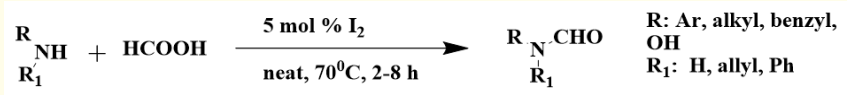

Figure 11: The N-formylation in the presence of molecular iodine.

S.-I. Hirashima, A. Itoh [63] has reported direct oxidation of methyl group in aromatic nucleus. A methyl group at an aromatic nucleus is oxidized directly to the corresponding carboxylic acid in the presence of molecular oxygen and catalytic hydrobromic acid under photoirradiation. The scheme used is shown in figure 12 .

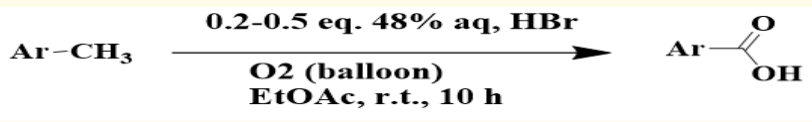

Figure 12: Direct oxidation of methyl group in aromatic nucleus.

M. Kirihara, A. Itou, T. Noguchi, J. Yamamoto [64] has reported oxidation of sulfides with $\mathrm{H}_{2} \mathrm{O}_{2}$. The scheme used is shown in figure 13.

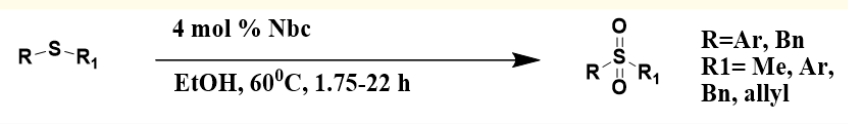

Figure 13: Oxidation of sulfides with $\mathrm{H}_{2} \mathrm{O}_{2}$.
S. Santoro, B. Battistelli, B. Gjoka, C.-w. S. Si, L. Testaferri, M. Tiecco, C. Santi [65] has reported oxidation of alkynes using ammonium persulfate and diphenyldiselenide as catalyst in aqueous media leads to 1,2-unprotected dicarbonyl derivatives or to hemiacetals starting from terminal alkynes. The scheme used is shown in figure 14.

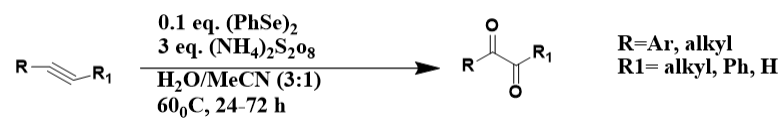

Figure 14: Oxidation of alkynes using ammonium persulfate and diphenyldiselenide.

J.G. Kima, D. O. Jang [66] has reported a simple, mild method for $\mathrm{N}$-formylation in the presence of indium metal as a catalyst under solvent-free conditions. It is also applicable to the chemoselective reaction of amines and $\alpha$-amino acid esters without epimerization. The scheme used is shown in figure 15.

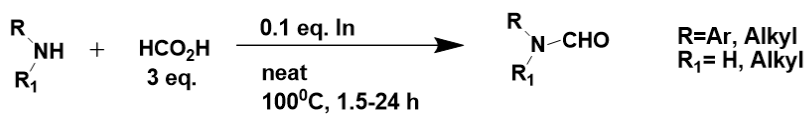

Figure 15: N-formylation in the presence of indium metal under solvent-free conditions.

S V Tiwari., et al. [67] has reported Facile Synthesis of Novel Coumarin Derivatives, Antimicrobial Analysis, Enzyme Assay, Docking Study, ADMET Prediction and Toxicity Study.

M R Bhosle., et al. [68] has reported DIPEAc promoted one-pot synthesis of dihydropyrido[2,3- $\left.d: 6,5-d^{\prime}\right]$ dipyrimidinetetraone and pyrimido[4,5- $d]$ pyrimidine derivatives as potent tyrosinase inhibitors and anticancer agents: in vitro screening, molecular docking and ADMET predictionst.

S V Tiwari G Nikalje., et al. [69] has reported Microwave-Assisted Facile Synthesis, Anticancer Evaluation and Docking Study of N((5-(Substituted methylene amino)-1,3,4-thiadiazol-2-yl)methyl) Benzamide Derivatives. 
A P G Nikalje., et al. [70] has reported Imidazole-thiazole coupled derivatives as novel lanosterol 14- $\alpha$ demethylase inhibitors: ionic liquid mediated synthesis, biological evaluation and molecular docking study.

P G Nikalje., et al. [71] has reported Ultrasound Assisted-synthesis and Biological Evaluation of Piperazinylprop- 1-en-2-yloxy-2Hchromen-2-ones as Cytotoxic Agents.

S V Tiwari., et al. [72] has reported Ionic Liquid-Promoted Synthesis of Novel Chromone-Pyrimidine Coupled Derivatives, Antimicrobial Analysis, Enzyme Assay, Docking Study and Toxicity Study.

M R Bhosle., et al. [73] has reported An efficient multicomponent synthesis and in vitro anticancer activity of dihydropyranochromene and chromenopyrimidine-2,5-diones.

S V Tiwari., et al. [74] has reported New 2-Oxoindolin Phosphonates as Novel Agents to Treat Cancer: A Green Synthesis and Molecule.

A P G Nikalje., et al. [75] has reported Ultrasound Promoted Green Synthesis, Docking Study of Indole Spliced Thiadiazole, $\alpha$-amino Phosphonates as Anticancer Agents and Anti-tyrosinase Agents.

A P G Nikalje., et al. [76] has reported Ultrasound-mediated synthesis, biological evaluation, docking and in vivo acute oral toxicity study of novel indolin-2-one coupled pyrimidine derivatives.

V S Dofe., et al. [77] has reported Ultrasound assisted synthesis of tetrazole based pyrazolines and isoxazolines as potent anticancer agents via inhibition of tubulin polymerization.

S V Tiwari., et al. [78] have reported ultrasound mediated onepot, three component synthesis, docking and ADME prediction of novel5-amino-2-(4-chlorophenyl)-7-substitutedphenyl-8,8a-dihydro-7h- $(1,3,4)$ thiadiazolo(3,2)pyrimidine-6-carbonitrile derivatives as anticancer agents.

\section{Conclusion}

Richard P. Feynman, says, "Nature does not care what we call it, nature just keeps on doing it." He tries to explain us that we must learn more and better about laws of nature and processes taking place in environment. Emphasis on the importance of green chem- istry and sustainable development for humans should be followed by us.

Green chemistry is one of the branch of science. The Green chemistry revolution provides an enormous number of opportunities to discover and apply new synthetic approaches using alternative feedstocks; eco-friendly reaction conditions, energy minimization and design of less toxic and inherently safer chemicals. In this review article we have seen many interesting examples of Green chemistry which can be applied in industries for synthesis, processing and using of chemical compounds. The main aim of green chemistry is to design an ideal method or process that starts from non-polluting initial materials, gives birth to no secondary products and requires no solvents to during the chemical conversion or to isolate and purify the product. However, more environmentally friendly technologies at the research stage do not guarantee that they will be implemented on an industrial scale. Adoption of environmentally benign methods may be facilitated by higher flexibility in regulations, new programs to facilitate technology transfer among academic institutions, government and industry and tax incentives for implementing cleaner technologies. Furthermore, the success of green chemistry depends on the training and education of a new generation of chemists. Student at all levels should be ready to introduce themselves to the philosophical world and practice of green chemistry.

\section{Acknowledgments}

The authors are thankful to the teaching and non teaching staff of Durgamata Institute of Pharmacy.

\section{Bibliography}

1. Anastas P T and Warner JC. "Green Chemistry: Theory and Practise”. Oxford University Press, Oxford 2.1 (1998): 155.

2. J Namieoenik and W Wardencki. "Solventless sample preparation techniques in environmental analysis". Journal of High Resolution Chromatography 20.2 (2000): 297.

3. Sato K., et al. "A “Green" Route to Adipic Acid: Direct Oxidation of Cyclohexenes with 30 percent hydrogen peroxide". Science 281 (1998): 1646.

4. United States Environmental Protection Agency, Basics of Green Chemistry (2017). 
5. Ando T., et al. "Alumina-supported fluoride reagents for organic synthesis: optimisation of reagent preparation and elucidation of the active species". Chemical Society, Perkin Transactions 2 (1986): 1133.

6. U Romano and F Garbassi. "The environmental issue. A challenge for new generation polyolefins". Pure and Applied Chemistry 72 (2000): 1383.

7. Nicolas N., et al. Actualite Chimique 11-12 (2012): 70.

8. Stashenko EE., et al. "Solid-phase microextraction with on-fibre derivatisation applied to the analysis of volatile carbonyl compounds". Journal of Chromatography A 886 (2000): 175.

9. Acardi A., et al. "Gold catalysis in the reactions of 1,3-dicarbonyls with nucleophiles". Green Chemistry 5 (2003): 64.

10. Scott G. “'Green' polymers”. Polymer Degradation and Stability 68 (2000): 1.

11. Tundo P., et al. "Process for the preparation of alkyl- and/or alkenylpolyglycol ethers with alkyl end-capping groups". ACS Symp. Ser., (Green Chemical Synthesses and Processes) 87 (2000): 767.

12. Anastas PT and Warner JC. "Green Chemistry, Theory and Practice". Oxford University Press (1998).

13. Dehmlov EV and Dehmlov SS. "Phase transfer catalyst". 3rd ed., Verlag Chemie, Weinheim (1993).

14. Starks CM., et al. "Phase transfer catalyst: Fundamentals, Application and Industrial Perspectives". Chapman and Hall, New York 2.1 (1994): 155.

15. Ahluwalia VK and Aggarwal R. "Org Synthesis: Special Techniques”. Narosa Publising House, New Delhi, (2001).

16. Merz A. "Phase-transfer-catalyzed Alkylation of Alcohols by Dimethyl Sulfate in an Aqueous System". Angewandte Chemie 12 (1973): 846.

17. Bari SS., et al. "Reactions accelerated by microwave radiation in the undergraduate organic laboratory". Journal of Chemical Education 69.11 (1992): 938.

18. Chen ST., et al. "Preparative scale organic synthesis using a kitchen microwave oven". Journal of the Chemical Society
(1990): 807.

19. Gedye RN., et al. "The rapid synthesis of organic compounds in microwave ovens". Canadian Journal of Chemistry 69 (1991): 700 .

20. Gruesbeck C and Rase HF. "Insolubilized Glucoamylase Enzyme System for Continuous Production of Dextrose". Industrial and Engineering Chemistry Process Design and Development 11 (1972): 74 .

21. Wetall HH., et al. "Scale-Up studies on immobilized, purified glucoamylase, covalently coupled to porous ceramic support". Methods Enzymology 44 (1976): 776.

22. Tosa T., et al. "Continuous production of L-aspartic acid by immobilized aspartase". Biotechnology Biology 15 (1973): 69.

23. Ando T and Welton T. Chemical Review 9 (2000): 18.

24. Starks CM., et al. "Phase transfer catalyst: fundamentals, applications, and Industrial perspectives". Chapman and Hall, New York (1994).

25. Alhuwalia VK and Aggarwal R. "Org synthesis: Special techniques”. Narosa Publishing House, New, Delhi (2001).

26. Merz A. "Phase-transfer-catalyzed Alkylation of Alcohols by Dimethyl Sulfate in an Aqueous System". Angewandte Chemie 12 (1973): 846.

27. Bari SS., et al. "Reactions accelerated by microwave radiation in the undergraduate organic laboratory". Journal of Chemical Education 69.11 (1992): 938.

28. Chen ST., et al. "Preparative scale organic synthesis using a kitchen microwave oven". Journal of the Chemical Society (1990): 807.

29. Gedye RN., et al. "The rapid synthesis of organic compounds in microwave ovens". Canadian Journal of Chemistry 69 (1991): 700.

30. Walton HM., et al. Biotechnology and Bioengineering (1973): 447.

31. Weetall HH., et al. "Covelent attachment of proteins to inorganic supports directly by activation with cyanogen bromide". Biotechnology and Bioengineering 17 (1975): 295. 
32. Tosa T., et al. "Continuous production of L-aspartic acid by immobilized aspartase”. Biotechnology and Biology 15 (1973): 69.

33. Yamamoto K., et al. "Continuous production of L-malic acid by immobilized Brevibacterium ammoniagenes cells". European Journal of Applied Microbiology and Biotechnology 3 (1976): 169.

34. Becker W and Pteil E. "Nucleoside Phosphorothioates". Journal of the American Chemical Society 88 (1985): 4299.

35. Shapiro SK and Ehninger DJ. "Methods for the analysis and preparation of adenosylmethionine and adenosylhomocysteine". Annals of Biochemistry 15 (1966): 323.

36. Rao G., et al. Biochimica et Biophysica Acta 715 (1982): 205.

37. Brummer SB and Gancy AB. "In Water and Aqueous Solutions: Structure, Thermodynamics and Transport Processes". Horne R.A., Ed., Wiely-Interscience (1970).

38. Kavanau JK. "Water and Solute-Water Interactions". HoldenDay, San Franciso (1964).

39. Saksena AK., et al. "Aqueous Diels-Alder Reactions of Electron Deficient 2-Arylfurans: A Highly Stereoselective Route to 2,2,5-Trisubstituted Tetrahydrofurans towards a Novel Class of Orally Active Azole Antifungals". Heterocycles 35 (1993): 129.

40. Williams DR., et al. "Intramolecular diels-alder cycloadditions of bis-diene substrates". Tetrahedron Letter 26 (1985): 1391.

41. Bressner J., et al. "Synthèses à l'aide de sulfones (XXIV) Synthèse stéréosélective d'oléfines par hydrogénolyse des vinylsulfones". Tetrahedron Letter 23 (1982): 3265.

42. Kaulen J and Schafer HJ. "Oxidation of Primary Alcohols to Carboxylic Acids at the Nickel Hydroxide Electrode". Synthesis (1979): 513.

43. Shono T., et al. "Electrochemical oxidation of alcohols using iodonium ion as an electron carrier". Tetrahedron Letter 20.2 (1979): 165-168.

44. Ruholi $\mathrm{H}$ and Schafer HJ. "Oxidative Cleavage of Vicinal Diols at the Nickel Hydroxide Electrode". Synthesis 1 (1988): 54-56.

45. Schmiht A. "On the action of bromine on room acid'. Liebigs Annalen 127 (1863): 319.
46. Kaupp G and Matthies D. "Organic gas - solid reactions with stilbenes, chalcones, and enamides". 120 (1987): 1897.

47. Zhang P., et al. "Ru-Zn supported on hydroxyapatite as an effective catalyst for partial hydrogenation of benzene". Green Chemistry 15 (2013): 152-159.

48. Chen G., et al. "Palladium supported on an acidic metal-organic framework as an efficient catalyst in selective aerobic oxidation of alcohols". Green Chemistry 15 (2013): 230-235.

49. Malik P., et al. "Bismuth (III) Oxide Catalyzed Oxidation of Alcohols with tert-Butyl Hydroperoxide”. Synthesis (2010): 37363740 .

50. Mao Z., et al. "Water-Compatible Iminium Activation: Highly Enantioselective Organocatalytic Michael Addition of Malonates to $\alpha, \beta$-Unsaturated Enones". Journal of Organic Chemistry 75 (2010): 7428-7430.

51. Jahani F., et al. "Pyridine 2,6-Dicarboxylic Acid as a Bifunctional Organocatalyst for Hydrophosphonylation of Aldehydes and Ketones in Water". Synthesis (2010): 3315-3318.

52. Nun P., et al. "Microwave-Assisted Neat Procedure for the Petasis Reaction". Synthesis (2010): 2063-2068.

53. Nikalje AP and Vyawahare D. "Facile green synthesis of 2, 4-substituted -2, 3- dihydro -1, 5 Benzothiazepine derivatives as novel anticonvulsant and central nervous system (CNS) depressant agents". African Journal of Pure and Applied Chemistry 5.12 (2011): 422-428.

54. Monguchi Y., et al. "Solvent-free Huisgen cyclization using heterogeneous copper catalysts supported on chelate resins". Green Chemistry 15.2 (2013): 490-495.

55. Gallo GMR., et al. "Production and upgrading of 5-hydroxymethylfurfural using heterogeneous catalysts and biomassderived solvents". Green Chemistry 15.1 (2013): 85-90.

56. Malhotra P., et al. "Microwave assisted synthesis and antiinflammatory activity of 3, 5-diaryl substituted -2 $\neg$ pyrazolines". International Journal of Pharmacy and Pharmaceutical Sciences2 (2010): 134-135.

57. García-Álvarez R., et al. "Metal-catalyzed amide bond forming reactions in an environmentally friendly aqueous medium: ni- 
trile hydrations and beyond". Green Chemistry 15 (2013): 4666.

58. Truscello AM., et al. "One-pot synthesis of aryloxypropanediols from glycerol: towards valuable chemicals from renewable sources". Green Chemistry 15.3 (2013): 625-628.

59. Jing C., et al. "CuSO4-catalyzed three-component reaction of $\alpha$-diazo ester, water and isatin: an efficient approach to oxindole derivatives". Green Chemistry 15.3 (2013): 620-624.

60. Nikalje AG., et al. "Green synthesis and pharmacological screening of novel 1,5-Benzothiazepines as CNS agents". IJPPS 2.2 (2010): 27-29.

61. Barata-Vallejo S and Postigo A. “ (Me3Si)3SiH-Mediated Intermolecular Radical Perfluoroalkylation Reactions of Olefins in Water". Journal of Organic Chemistry 75 (2010): 6141-6148.

62. Kim JG., et al. "Facile and Highly Efficient N-Formylation of Amines Using a Catalytic Amount of Iodine under Solvent-Free Conditions". Synlett (2010): 2093-2096.

63. Hirashima SI and Itoh A. "Synthesis of Benzoic Acids by Aerobic Photooxidation with Hydrobromic Acid". Synthesis 11 (2006): 1757-1759.

64. Kirihara M., et al. "Tantalum Carbide or Niobium Carbide Catalyzed Oxidation of Sulfides with Hydrogen Peroxide: Highly Efficient and Chemoselective Syntheses of Sulfoxides and Sulfones". Synlett 10 (2010): 1557-1561.

65. Santoro S., et al. "Oxidation of Alkynes in Aqueous Media Catalyzed by Diphenyl Diselenide". Synlett 9 (2010): 1402-1406.

66. Kima JG and Jang D O. "Indium-Catalyzed N-Formylation of Amines under Solvent-Free Conditions". Synlett 8 (2010): 12311234.

67. Tiwari S V., et al. "Facile Synthesis of Novel Coumarin Derivatives, Antimicrobial Analysis, Enzyme Assay, Docking Study, ADMET Prediction and Toxicity Study". Molecules 22.7 (2017): 1172.

68. Bhosle M R., et al. "DIPEAc promoted one-pot synthesis of dihydropyrido[2,3-d:6,5-d']dipyrimidinetetraone and pyrimido[4,5-d]pyrimidine derivatives as potent tyrosinase inhibitors and anticancer agents: in vitro screening, molecular docking and ADMET predictions". New Journal of Chemistry 42.23 (2018): 18621-18632.

69. Tiwari S V., et al. "Microwave-Assisted Facile Synthesis, Anticancer Evaluation and Docking Study of N- ( (5- (Substituted methylene amino)-1,3,4-thiadiazol-2-yl)methyl)". Benzamide Derivatives 22.23 (2017): 995.

70. Nikalje A P G., et al. "Imidazole-thiazole coupled derivatives as novel lanosterol 14- $\alpha$ demethylase inhibitors: ionic liquid mediated synthesis, biological evaluation and molecular docking study". Molecules 27.2 (2018) : 592-606.

71. Nikalje P G., et al. "Ultrasound Assisted-synthesis and Biological Evaluation of Piperazinylprop- 1-en-2-yloxy-2H-chromen2-ones as Cytotoxic Agents". Letters in Drug Design and Discovery 14.10 (2017): 1192-1205.

72. Tiwari S V., et al. "Ionic Liquid-Promoted Synthesis of Novel Chromone-Pyrimidine Coupled Derivatives, Antimicrobial Analysis, Enzyme Assay, Docking Study and Toxicity Study". Molecules 23.2 (2018): 440.

73. Bhosle MR., et al. "An efficient multicomponent synthesis and in vitro anticancer activity of dihydropyranochromene and chromenopyrimidine-2,5-diones". Synthetic Communications 48.16 (2018): 2046-2060.

74. Tiwari SV., et al. "New 2-Oxoindolin Phosphonates as Novel Agents to Treat Cancer: A Green Synthesis and Molecular Modeling”. Molecules 23.8 (2018): 1981.

75. Nikalje A G., et al. "Ultrasound Promoted Green Synthesis, Docking Study of Indole Spliced Thiadiazole, $\alpha$-amino Phosphonates as Anticancer Agents and Anti-tyrosinase Agents". Anti-Cancer Agents in Medicinal Chemistry 18.9 (2018): 1267-1280.

76. Nikalje A P G., et al. "Ultrasound-mediated synthesis, biological evaluation, docking and in vivo acute oral toxicity study of novel indolin-2-one coupled pyrimidine derivatives". Research on Chemical Intermediates 44.5 (2018): 3031-3059.

77. Dofe VS., et al. "Ultrasound assisted synthesis of tetrazole based pyrazolines and isoxazolines as potent anticancer agents via inhibition of tubulin polymerization". Bioorganic and Medicinal Chemistry Letters 30.22 (2020): 127592. 
78. Tiwari SV., et al. "Ultrasound Mediated One-Pot, Three Component Synthesis, Docking and ADME Prediction of Novel 5-Amino-2- (4-chlorophenyl)-7-Substituted Phenyl-8,8a-dihydro-7H- $(1,3,4)$ thiadiazolo $(3,2-\alpha)$ pyrimidine-6-carbonitrile Derivatives as Anticancer Agents". Molecules 21.8 (2016): 894.

\section{Assets from publication with us}

- Prompt Acknowledgement after receiving the article

- Thorough Double blinded peer review

- Rapid Publication

- Issue of Publication Certificate

- High visibility of your Published work

Website: www.actascientific.com/

Submit Article: www.actascientific.com/submission.php

Email us: editor@actascientific.com

Contact us: +919182824667 